[PROC. OF JSCE No.425/IV-14 (Infrastructure Planning and Management) January 1991]

\title{
THE INFLUENCE OF ROUTE GUIDANCE ADVICE ON ROUTE CHOICE IN URBAN NETWORKS
}

\author{
By Peter BONSALL*
}

\section{INTRODUCTION}

This paper is concerned with the impact of in-vehicle route guidance and information (IVRGI) systems on route choice. IVRGI systems include directional aids (eg Toyota's NAVICOM), current-position displays (eg ETAK's NAVIGATOR or Nissan's DRIVEGUIDE), real time traffic information transmissions (eg via car radios using the HAR, ARI or RDS systems), real time congestion displays (eg General Logistics' TRAFFICMASTER), guidance based on historic data (eg Mercedes Benz' Routen-Rechner) and guidance based on real time data (eg Siemens' ALISCOUT). Each of these have the ability to influence drivers' choices of routes and each might affect these choices in different ways.

There is currently considerable government interest in the development of IVRGI systems as witnessed by the promotion of programmes such as DRIVE in Europe and RACS/AMTICS in Japan and by the recent Report to Congress in the USA. This interest is partly a reflection of industrial-commercial strategy by the respective governments but also reflects a belief that such systems might assist in the solution of traffic problems (see Jeffery, 1981; OECD, 1988).

It is suggested that IVRGI systems can produce benefits to the traffic system in four ways:

(1) Firstly and most fundamentally, by improving peoples' knowledge of the network and by assisting them to find efficient routes, some of the resources currently wasted in unnecessary time or mileage can be recovered (see for example Jeffery et al. 1987). Estimates of the magnitude of such "wastage" range from $2 \%$ to $12 \%$ of current total miles and minutes (see Wootton et al. 1981)

(2) Secondly, it is thought that by reducing unnecessary mileage, traffic volumes, and hence congestion, can be reduced.

(3) Thirdly, it is thought that by linking IVRGI with traffic control (see CARGOES, 1989) and, perhaps, road pricing systems (see Brett and Estlea, 1989) all three systems could become more effective.

(4) Fourthly, it is suggested that, by manipulating the information or guidance provided to drivers it might be possible to discourage them from using routes which are environmentally sensitive and that it might be possible to bring about routing patterns that are more globally efficient (the so called "system optimum”).

* Senior Lecturer in Transport Planning, Institute for Transport Studies, University of Leeds, LEEDS LS 29 JT, UK

Keywords: route choice, IVRG, guidance, simulation game, choice model 
The last of these is the subject of most debate : detractors argue that drivers are unlikely to accept advice which is not in their own, selfish, best interest and that unless system-optimal guidance is backed up by differential road pricing they will tend to ignore it. Even in the absence of deliberate attempts by network managers to promote system-optimal or environmentally sound routing, users may sometimes believe that the advised route is not best for them and, of course, they may be right ; either because of "gaps" in the guidance system's knowledge of the network or of up-to-the-minute traffic conditions or because the system and the user have different routing criteria. In such circumstances the drivers might accept the advice only selectively, they might use it to extend their knowledge of the network but might ignore any advice that they suspected as being sub-optimal from their own point of view.

It has been suggested that, if drivers are discriminating in their acceptance of guidance, greater system benefits might be achieved by having a large number of drivers following user-optimal guidance than a few following system-optimal guidance. Against this background the manner in which drivers' choice of routes is influenced by IVRGI systems is crucially important to any assessment of their impacts on network performance and environmental conditions.

\section{ROUTE CHOICE PROCESSES IN THE ABSENCE OF IVRGI}

There have, in the last two decades, been several empirical studies of the factors affecting drivers' choice of routes and it is perhaps useful to summarise the main findings here. In the interurban context, it is generally agreed that, for most types of journey, most drivers are attempting to minimise travel time or distance (taken together they account for between $75 \%$ and $90 \%$ of all choices-see Outram and Thompson, 1978). However, a significant proportion of interurban travellers simply follow main roads or signposted routes-presumably because they are unfamiliar with the networks through which they are passing (Wootton et al. 1981).

In the urban context the situation is much less clear cut; some researchers have concluded that time minimisation is the dominant criterion while others have noted the importance of aspects such as road type or hierarchy (Wachs, 1967; Ueberschaer, 1971; Ben Akiva et al. 1984) avoidance of congestion (Wachs 1967 ; Ueberschaer, 1971 ; Bonsall and May, 1986) and avoidance of stops and traffic signals (Ueberschaer, 1971; Huchingson et al. 1977). Recent research conducted as a preliminary part of an investigation of drivers' requirements for route guidance (CARGOES, $1990 \mathrm{~b}$; Bonsall and Parry, 1990 a) compared drivers' route choice criteria in four major cities in Europe. The route choice criteria were seen to vary between the cities and according to different journey purposes (it is not possible to determine whether the differences between cities represent cultural differences or network conditions). The questionnaire on which these results are based distinguished between a number of time related criteria and it is interesting to note that, although simple time minimisation is important for all types of journeys, in no case is it the main criterion for most respondents ; for some journey purposes it is very much a minority concern. Avoiding congestion and certainty of arrival time are seen as more important than time minimisation by a substantial proportion of drivers.

Several attempts have been made to determine whether drivers succeed in selecting routes which achieve their stated objectives (eg Outram and Thompson, 1978; King, 1988). Such studies have been hampered by the fact that, except in the case of distance minimisation, most criteria are subjective or time variant and thus difficult to measure objectively and accurately. Nonetheless, following a recent study of commuters' route choice in the Santa Monica Freeway Corridor of Los Angeles, Al Deek et al. (1989) report that, in "normal" conditions, most drivers were successfully time minimising but that they were not adjusting successfully to situations caused by sporadic congestion, a finding which, as the authors point out, highlights the value to drivers of having access to real-time information on network conditions.

A number of researchers have looked at drivers' perception and use of alternative routes. Benshoof (1970) found that although most commuters to work in an urban area thought that they had two or three 
alternative routes, the majority said they always stuck to the same one. Wright (1976) found that drivers' tended to use the same route day after day largely because they had limited knowledge of alternatives. On the basis of study surveys in Leeds (UK), Bonsall and May (1986) found that, in a six day period, only $40 \%$ of commuters used the same route on all six days and that, when interviewed at an urban stop line, around $5 \%$ of peak hour drivers claimed to be following routes they had "rarely or never" used before and $15 \%$ claimed not to have selected a precise route before setting out-the actual route being decided in the light of prevailing conditions.

A number of empirical studies have examined the way in which drivers adjust their routes to varying circumstances. Heathington et al. (1971) studied diversions in response to accidents while Stephenson (1981), and Bonsall and May (1986) have studied the process by which regular commuters adapt to network changes-both studies report a period of experimentation with alternative routes prior to selection of a new norm.

These and other empirical studies of route choice have, together with an input from behavioural scientists, lead to the formulation of conceptual models of the process of route choice. Important features of such conceptual models include the distinction between strategic planning (based on expected conditions) and tactical adjustment (in the light of conditions actually met), the existence of temporal disequilibrium (due to inertia in drivers' adjustment to new conditions), bounded rationality, attitudes to uncertainty and complex search strategies.

In stark contrast to the above, most of the models currently used to represent route choice were developed in the context of assignment modelling where the main concern is with predicting realistic flows on links rather than route choices. An important features of such models is the representation of the interaction between link travel times and flows-fast links attract traffic but are, in the process, made slower. Most of these models have been concerned with predicting average conditions over a period of time rather than actual conditions on a particular day. Many of them have sought to generate equilibrium flow patterns which might be expected to come about after a period of time. Achievement of a Wardrop equilibrium solution, wherein no driver can unilaterally reduce his travel cost by modifying his current routing pattern (Wardrop, 1952), is a widely used test of the success of such models.

Some authors (eg Horowitz, 1984) have sought to interpret the approach to equilibrium in behavioural terms as a learning process but most macro models have been content to accept equilibrium as a desirable goal with little consideration of the behavioural issues involved.

Most route choice models have assumed that drivers are seeking to minimise their travel time or some linear weighted combination of time and distance. An interesting recent exception to this general rule is the model described by Breheret et al. (1990) which allows routes to be influenced by the existence of queues to an extent beyond those queues' contribution to travel time. More radically, some route choice models have incorporated discrete choice submodels whereby drivers select between predefined sets of routes in terms of a variety of attributes. Kobayashi (1979) used a multiple regression model to select between routes characterised in terms of length, number of lanes, percentage of trunk lanes and numbers of turns. Ben Akiva et al. (1984) used a nested logit model to select between routes characterised by factors such as time, distance, congestion, traffic signals, scenic quality and hierarchy. In general, however, the problems of incorporating such constructs within an equilibrium model have proved insurmountable and the simple time minimisation approach remains dominant.

Recent developments in assignment modelling have been more concerned with the incorporation of network dynamics (wherein flow and congestion patterns change over time), stochastic choice (which recognises differences in the perception, or levels of knowledge of, link costs by selecting values for different groups from a distribution about the mean-an idea put forward by Burrell (1968) and subsequently developed in the Stochastic User Equilibrium (SUE) models, and day-on-day variability. All of which are, as we will see in later sections, fundamental to a proper representation of route choice in 
the context of IVRGI.

\section{EMPIRICAL STUDIES OF THE EFFECT OF IVRGI SYSTEMS ON ROUTE CHOICE}

Anecdotal evidence on driver reaction to roadside variable message signs (VMS) in the context of parking advice systems and congestion avoidance systems, such as those on the German motorway system, suggests that acceptance of the advice depends crucially on its credibility. It seems that drivers do not accept the advice unquestioningly, some simply ignore it believing it to be unreliable, while others deliberately do the opposite of what is advised on the assumption that other drivers will be following the advice leaving the road, or parking spaces, free for themselves.

IVRGI systems have been in existence for less time than roadside VMS and consequently even less is known about their effect on drivers' route choice. A number of studies have however used questionnaires and interviews to gauge possible reactions. King's (1986) work suggested that most drivers were fairly confident of their ability to navigate unaided by IVRGI. Shirazi et al. (1988) reported that $17 \%$ of drivers thought that existing (low tech) sources of information were quite adequate and that the credibility of information was crucial (almost $90 \%$ of drivers said they would leave the freeway if they had reliable information about an alternative quicker route). Bonsall and Parry (1990 a) reported that drivers in a sample of major European cities were generally fairly happy with existing information sources but that they would find invehicle information based on real-time data very helpful for adjusting their "usual" route in the light of conditions on a specific day. Drivers on regular journeys preferred information to guidance-many of them expressing the opinion that they did not want to surrender their route choice to a machine since they believed that, provided they had access to real-time data, they could outperform it.

A particularly valuable opportunity to study drivers' response to dynamic invehicle route guidance was recently provided by LISB (the Berlin trial of Siemen's ALISCOUT system). Questionnaire surveys among the 300 private car drivers involved in the LISB trial were conducted after the drivers had the equipment in their cars for a year or more. We will, in due course, be reporting the results in greater detail elsewhere but the main results are summarised here for convenience.

Most drivers did not appear to have been influenced by LISB to alter their usual route on regular journeys to or from work. About one fifth of drivers had changed their normal route as a result of LISB advice but a similar proportion said they would not vary their route even if LISB advised them to. About $2 / 3$ said that they ignored the adivised route if it appeared unaware of short cuts on secondary roads and about half said that LISB had taught them some new routes that they would now continue to use even without LISB. Adherence to LISB advice was higher for journeys in unfamiliar areas than for journeys in familiar areas ( $87 \%$ as compared to $72 \%$ of respondents). The most common reasons for not following the advice were that the advised direction did not accord with the supposed crowfly direction, that the advice was given too late, that the driver saw no good reason to deviate from his normal route, and that the driver had thought that the advised route was likely to be congested.

Interesting and illuminating though the Berlin results are, they do not provide a quantitative basis for the specification or calibration of models. The data is based on subjective recall by participants rather than objective observation by disinterested parties and relates to generalities of behaviour over a period of time rather than to actual reactions to specified sets of circumstances. In order to overcome these problems we considered making use of centrally logged records of LISB users' route choices but practical problems encountered when trying to process the data proved insurmountable. It is understood that there is a similar proposal to use central logs to study users of the PATHFINDER system which forms part of California's PATH programme. It is also likely that the evaluation packages proposed to accompany IVRGI implementations under the European DRIVE 2 initiative (starting in 1992) will incorporate some careful monitoring of impacts on drivers' route choice.

However, pending the availability of such results there is little quantified evidence from the field on 
which to base models of driver reaction to IVRGI.

\section{INTERACTIVE SIMULATIONS AS A SOURCE OF DATA ON DRIVERS REACTION TO IVRGI}

Given the absence of a reliable body of quantitative evidence on the impact of IVRGI on drivers' choice of routes and the urgent need for such data in model based analyses, the research team at ITS, Leeds University developed an interactive simulation model ("IGOR") with which to collect the necessary data (Bonsall and Parry, 1990 b). IGOR runs on a portable PC and is based on a small network (30 two-way links, 19 nodes). "Drivers" are asked to make a series of journeys, from specified origins to specified destinations and are free to select their own routes. IGOR presents them with a screen describing the situation at each junction they come to and invites them to select their preferred exit from that junction by pressing an appropriate key. Among other information presented at each junction is:

(1) The amount of congestion (if any) visible on each exit link

(2) The alignment of each exit relative to the "crowfly" direction to the destination

(3) The size of road at each exit

(4) Which exit (if any) is the signposted route to the destination

(5) The amount of traffic turning into each of the exits

(6) Which exit is recommended by the (time minimising) IVRG system

Some journeys are made in a network for which a map is available and with which the driver can become familiar while other journeys are made in an "unknown" network with no map available.

Traffic conditions in the IGOR networks vary from one run to another to reflect the different levels of flow expected at different times of day (which is controlled deterministically) and the variation in traffic from one day to another (which is represented stochastically).

The advice provided to drivers in IGOR is generally based on the minimum time route to the destination given current traffic conditions (including the stochastic variation). In this respect it reflects the goal of dynamic systems such as ALISCOUT. To make it more realistic, however, we have deliberately degraded the quality of advice by making certain links "invisible" to the guidance system (thus reflecting their accidental or deliberate exclusion from the guidance network). Also, because we were particularly interested in drivers' reaction to advice of different qualities, drivers were deliberately given a known amount of bad advice.

The circumstances faced and advice received by each driver at each junction are recorded on a data disk along with the decision made by the driver. Also recorded on the disk are certain characteristics of the driver (age, sex, driving experience, and various items of attitudinal data) which are obtained via an interactive questionnaire which precedes the main IGOR simulation. Analysis of the choices made can therefore be conducted without the need for laborious data coding and input.

IGOR differs from other simulation-based investigations of driver response to IVRGI (eg Jovanis and Kitamura, 1989 ; Stephens, 1990; Ayland, 1991) in its concentration on route choice and the acceptance/rejection of advice rather than on ergonomic aspects and differs from Mahmassanis' work with interactive simulation techniques (eg Mahmassani and Stephan, 1988) in its concentration on tactical rather than strategic decisions and its lack of concern for network equilibrium.

IGOR exists in two versions-the original English and a French translation. These two versions were used on the premises of large companies and other organisations in the UK and France during the summer of 1990 to collect data from almost 350 individuals (the UK data was collected by staff from the University of Leeds while that in France was collected by INRETS). Since each individual made several "journeys" and each "journey" consisted of several decisions, the resulting datafile contains information on over 11000 decisions. The data has been analysed as part of a DRIVE project (CARGOES, $1990 \mathrm{c}$ ) and a number of interesting conclusions result: 
(1) Acceptance of an item of advice is very dependent on the quality of that advice (completely accurate time minimising advice was accepted on about $80 \%$ of occasions while advice that would, if followed, result in journey times of at least $40 \%$ higher than the minimum time route was followed on only about $25 \%$ of occasions);

(2) Drivers' acceptance of advice varies with their knowledge of the network (when driving on a network they had become familiar with drivers accepted about $67 \%$ of advice but when driving for the first time in a new network without a map to consult, advice was accepted on about $80 \%$ of occasions);

(3) Drivers are prepared to adhere to an occasional piece of bad advice provided that their previous experience of advice has been good ( $74 \%$ of non optimal advice is accepted by people whose previous advice has provided routes averaging within $3 \%$ of the best possible travel time but only $34 \%$ is accepted by those whose previous advice has provided routes averaging more than $20 \%$ greater than the best possible travel time ;

(4) Young drivers seem less ready than older drivers to accept advice, even good advice;

(5) As drivers get closer to their destinations they appear more able to discriminate between good and bad advice;

(6) Advice that sends the driver in what he perceives to be the correct (crowfly) direction is much more likely to be accepted than advice that conflicts with the drivers' sense of direction (optimal advice is accepted on about $90 \%$ of occasions if it conforms with the crowfly direction but on only about $53 \%$ of occasions if it does not. Non optimal advice is accepted on about $73 \%$ of occasions if it conforms to the crowfly direction and on only about $20 \%$ of occasions if it does not);

(7) Non optimal advice is very unlikely to be followed if it sends the driver along a route that no other drivers are using;

(8) Non optimal advice is more likely to be followed if it adheres to the signposted route and if it uses uncongested roads ;

(9) Drivers who say that they choose their routes to work in order to minimise distance seem very prepared to accept advice - even non optimal advice (distance minimisers accept $71 \%$ of non optimal advice whereas time minimisers accept only $48 \%$ of non optimal advice).

These and other findings are leading us to a much improved understanding of the circumstances in which drivers will and will not accept guidance. This will be of assistance not only in the design of guidance strategies but in the prediction of route choice decisions. The intended use of IGOR data in the specification of route choice models will be described in section 7 below.

Further development of the IGOR model to examine other aspects of route choice with and without route guidance or information in its various forms, is discussed elsewhere (Bonsall and Parry, $1990 \mathrm{~b}$ ).

\section{SYNOPSIS OF EVIDENCE ON THE IMPACT OF IVRGI ON ROUTE CHOICE}

The conclusions to be drawn from the empirical evidence from the field and from IGOR is that route choice will be influenced by IVRGI but only if the information or guidance is credible. This credibility will depend on how up to date it is, how detailed a network it is based on and on the existence of corroborating or conflicting evidence on the ground.

Drivers making regular journeys are particularly likely to reject guidance and to criticise its accuracy. Their prejudices are likely to be reinforced if they do follow the advice on a particular day and find it less good than their normal route usually is. The provision of information to justify why a particular route is advised on a particular day would perhaps improve its credibility.

Jovanis and Kitamura (1989), and Mahmassani and Jayakrishnan (1989) have suggested that a drivers' decision on how to react to an item of information or guidance will reflect their assessment of the relative probabilities of arriving at their destination by the desired time if they take one route rather than another. If this is so it might further reinforce drivers' tendency to stick to known routes rather than risk new ones 
even if advised to do so.

\section{EXISTING MODELS OF ROUTE CHOICE IN THE CONTEXT OF IVRGI}

Several studies have attempted to model the impact of the introduction of IVRGI on network performance. In some cases a particular IVRGI implementation has been the subject of the study; for example CACS in Tokyo (Kobayashi, 1979). AUTOGUIDE in London (Smith and Russam, 1989) while in other cases the aim has been to examine the impact of a range of IVRGI systems in a variety of networks (eg Van Aerde and Yagar, 1990 ; Brecheret et al. 1990 ; Van Vuren and Watling, 1991).

Most studies have recognised that the introduction of IVRGI systems creates two classes of driver (the equipped and the non equipped), that both groups will be impacted, but that some means has to be found of representing the equipped group's access to extra imformation about network conditions. There have been a number of different approaches to this, each of which concentrate on representing the relative "ignorance" of the non-equipped group.

A popular approach, which has been applied by several authors (see for example Tsuji et al. 1985 ; Koutsopoulos and Lotan, 1989 ; Breheret et al. 1990 ; and Van Vuren and Watling, 1991) is to assign both groups using stochastic user equilibrium methods but with the variance (=misperception/ignorance) around the mean link times being higher for the non-equipped group. At the limit the equipped group can be assigned with zero variance (=perfect knowledge) equivalent to a deterministic solution. This is a theoretically elegant approach but it has important limitations;

(1) Firstly its results will depend on the values chosen for the variances but, as Van Berkum and Van der Mede (1990) point out, the dependence of the variance on drivers' levels of knowledge is not (yet) understood

(2) Secondly, and more fundamentally, as pointed out by Boyce (1988) and others, an approach based on representation of medium term equilibrium or average conditions cannot be expected to reflect the particular benefits that IVRGI is intended to give in respect of day-specific incidents or sporadic congestion.

In order to capture these benefits a number of researchers have attempted to model what happens on a particular day when one group of drivers know about day-specific incidents while the rest are basing their route choice on average conditions. Perhaps the simplest example of this approach is that incorporated as one of the options in the INTEGRATION model (Van Aerde et al. 1989) and described by Rakla et al. (1989) ; the non-equipped drivers are assigned according to uncongested costs while the equipped drivers are assigned according to congested costs. Clearly this method, in assuming such naive behaviour by non-equipped drivers, will overemphasise the impact of IVRGI.

A more realistic method (as used by Smith and Russam, 1989, and Watling, 1990) has been to assign the non-equipped according to routes based on the medium term user equilibrium solution and then, after perturbing the demand matrix so as to represent actual conditions on a particular day, to assign the equipped drivers in the light of these conditions. The model used by Watling had been developed from SATURN as part of a DRIVE project (ASTERIX, 1989) and can be used to assign equipped drivers in the light of conditions resulting from specific perturbations of network supply as well as of the demand matrix. These methods, like the INTEGRATION model, emphasise the particular benefits of an IVRGI that can inform its users about real-time conditions and incidents, but since it denies non-equipped drivers the possibility of tactical adjustment to conditions on a particular day, it will tend to inflate these benefits and over emphasise the way in which benefits to equipped drivers decline as they form an increasing proportion of the driving population.

All the above methods have assigned the equipped drivers according to a user-oriented objective function. A comparison of this with what might happen if they were routed so as to minimise total system costs (ie the system-optimum solution) has been attempted using a variety of models. In the model 
described by Van Vuren et al. (1989) the non-equipped drivers are assumed to follow UE routes, in that described by Van Vuren and Watling (1991) they follow SUE routes, and, in that described by Van Aerde and Yagar (1990) they are assumed to route themselves according to uncongested speeds. Several authors have used modified versions of the CONTRAM model to compare system-optimal with user optimal routings (see Smith and Russam, 1989 ; Breheret et al. 1990 ; and Smith and Ghali, 1991). Smith and Russam's model has also been used to demonstrate the effect of restricting guided vehicles to a partial network (excluding minor roads). However, none of these models allow for the fact that equipped drivers might in practice object to being sent on system-optimal routes or restricted to partial networks and their results must therefore be seen as providing an upper bound of what might be achieved with IVRGI.

A number of researchers have used detailed simulation models such as NETSIM, which are not in the normal sense "route choice models", to examine what might happen in local area networks if (some) drivers were kept informed about conditions ahead. A recent example is provided by Mizar's NEMIS model (CARGOES $1990 \mathrm{a}$ ). The model considers, in great detail, the performance of a sub area within a larger network. Basic demand and routing patterns are accepted from a macro model (which might determine average conditions from an equilibrium assignment) but the concern of NEMIS is on how the network would perform with given interruptions to capacity at a particular time on a particular day. Minute-by-minute simulation is used to test the effect of rerouting the equipped drivers according to a number of different strategies (eg with multi-routing to avoid feedback effects and with different congestion detection and prediction algorithms).

With the arguable exception of those models which route equipped vehicles according to some form of stochastic equilibrium, all the above methods assume that equipped drivers will follow guidance and will make rational use of invehicle information to minimise their objective function (normally time). As we have seen in sections 3,4 , and 5 this is not a realistic assumption; the evidence is that drivers are very selective in their acceptance of advice and reaction to information.

An interesting approach to the representation of this phenomenon has been implemented by Mahmassani and Jayakrishnan (1989). In their model (which is developed from the MPSM simulator (see Chang et al. 1985)) drivers are assumed to retain their original route unless the newly recommended route is perceived as likely to represent more than a given percentage improvement on the original route. The model, which has a 0.1 second update, is currently based on a fairly simplistic network and choice of original route but the underlying concept has obvious appeal because it can represent inertia in tactical route selection and may also be said to reflect drivers' attitudes to the uncertainty inherent in using a previously unknown route.

\section{TOWARDS A NEW MODEL OF ROUTE CHOICE IN THE CONTEXT OF IVRGI}

Given what has been learned from the models and empirical work described above it is now possible to produce a specification for a more comprehensive model of route choice with and without guidance.

Such a model would ideally be able to indicate the performance (in terms of network flows, times and costs and the incidence of impacts) of the different forms of IVRGI. Our conclusion is that this cannot be done without a realistic representation of :

(i) route choice by non-equipped drivers

(ii) drivers' reactions to network conditions on a specific day

(iii) the IVRGI system itself

(iv) equipped drivers' acceptance/non-acceptance of advice.

The basic form of the model is determined by the need to be able to represent the performance of IVRGI in the context of sporadic and dynamically evolving congestion. It follows that the model must represent conditions as they might evolve on a particular day rather than being concerned with average or equilibrium conditions. If the average performance of IVRGI over a period of time is required it will be necessary to 
consider a number of days and then derive an average performance rather than take an average day. There is no obvious analytical solution to this and a dynamic simulation of conditions on individual days therefore seems necessary.

A further basic requirement would appear to be that we should distinguish between strategic route planning and tactical adjustments made in the light of IVRGI and conditions met on the road. An attractive approach to this would be to have the model run in two phases. In the first phase a SUE solution would be sought to represent the average conditions on the basis of which strategic route choices might be assumed to be made, while in the second phase a day-specific simulation would be employed to represent tactical adjustments in the light of IVRGI and conditions actually met.

In order that the route choices in the first phase model are realistic the demand matrix would be divided into groups, each group having its own route choice criteria. Most groups' criteria could be based on combinations of travel time and distance. For some groups the travel time would be weighted to give greater disutility to time spent on congested links or on links whose speed is very variable. Sampling from distributions around the means would provide a representation of perception errors and personal preferences. It is also possible that, by using skewed functions for some groups, preferences for particular types of road (eg major highways as favoured by unfamiliar drivers) could be represented. Another important feature of the first phase model would be that the cost skims and full backnode tables would be retained for use on the second phase model where they will show the best (perceived) routes to the destination from each junction via every exit and not just the preferred exit.

The second phase of the model would ideally be an event-based microsimulation of individual drivers on a specific day. It would begin with a randomisation process by which a day-specific demand matrix and day-specific reductions in network capacity (to represent roadworks etc.) would be defined. The demand matrix would then be transformed into an ordered list (depending on departure time) of individual drivers labled with their characteristics including destination, whether equipped with IVRGI, their strategic route and cost skims (this at last having been defined for particular groups of driver in the first phase of the model).

Events in the ordered list would then be processed in turn. Thus the first driver would set off and the program would calculate the time it would take him, given current conditions, to reach his first junction/decision point. His arrival at that point would be an event and would be slotted into the appropriate place in the ordered list. Housekeeping records of the current flow or queue on individual links would be updated and the next event in the ordered list would be dealt with... and so on until the list was exhausted or the end of the period to be simulated was reached.

Whenever an event represented a possible tactical change in route (depending on network configuration all events might be in this category) a subroutine would be called to consider whether a tactical change is to be made. The basic rule would be that the strategic route would be adhered to unless new information (whether from the IVRGI system or from observation of actual conditions in the local network) indicated that the link costs were likely to be perceived as significantly different from those costs on which the strategic route choice was based. If new information does merit a reconsideration of the route to be taken by an equipped or by a non-equipped driver then the following test would be made :

change route if $C_{p}+\Delta_{p}<C_{s}+\Delta_{s}+\alpha_{d i}$

where $C_{p}$ and $C_{s}=$ perceived costs to reach the destination via the potential new route and the strategic route respectively (these costs having been stored from the cost skims of the first phase model)

$\Delta_{p}$ and $\Delta_{s}$ are perceived changes $(+$ or - ) to the above costs of which the driver has now become aware along the potential new route and the strategic route respectively $\alpha_{d i}$ is a parameter for drivers of type $d$ in respect of new information from source $i$. $\alpha$ represents inertia in favour of staying on the strategic route 
If a driver did divert from his original strategic route by taking an alternative exit from a particular junction then his new strategic route would thenceforward follow his minimum cost skims to the destination via that exit.

The $d$ subscript on the $\alpha$ parameter allows for the fact that different drivers are likely to respond to "new" information in different ways - this might reflect their familiarity with the network, their journey purpose (or, more importantly perhaps, the fixedness of their schedule) or their previous experience of the realiability of "new" information of the type in question.

The $i$ subscript on the $\alpha$ parameter allows drivers to respond differently to different types of "new" information. We might, for example, expect different responses to each of the following:

(i ) visible, but unexplained, differences from the expected pattern of congestion (eg queues where they were not expected or no queues where they were expected)

(ii) visible and explained differences from the expected pattern of congestion but backed up by a visible cause (eg a traffic accident)

(iii) road signs

(iv) roadside VMS advice

(v) invehicle information

(vi) invehicle guidance

(vii) invehicle guidance backed up by "reasons" for the guidance.

(The response to items (iii) - (vii) would differ according to whether it was corroborated by, or apparently in conflict with, other evidence such as compass directions, or visible queues).

Values for the $\alpha$ parameter for each of the above have been, or could be, estimated from IGOR but ought clearly to be tested using sensitivity analysis.

Different types and qualities of IVRGI could be represented in the model by appropriate specification of the new information supplied at decision points. Thus the new information could be made available simultaneously throughout the network (as broadcast information might be) or only after the driver had passed specified points (analagous to beacon based systems). Similarly the information or guidance could be based on recent, current or predicted conditions, could relate to the complete network or only a subset of links and could be based on the minimisation of time or some other quantity on behalf of the individual drivers or could be designed to seek system-optimal routeing.

Clearly each IVRGI system, and each scenario (eg levels of penetration of IVRGI in the fleet), to be tested would require separate runs of the day-specific simulation. Indeed several runs for each system or scenario might be required if sensitivity testing was to be included. One run of the first phase (the medium term equilibrium basis of strategic route choice) could, however, be used as the starting point for a whole series of such tests.

Although the day-specific simulation model would ideally incorporate detailed representation of junction and link performance by simulating queueing patterns, gap acceptance, signal phasing and so forth, the computation requirements would be enormous for all but the very smallest networks. Simplification of the representation of traffic dynamics by relying on speed-flow curves and, perhaps, treating groups of vehicles rather than individual ones might therefore be necessary if the model is to be a practical tool for testing extensive networks. If such simplification becomes necessary the appropriate misspecification tests should, of course, be conducted.

The model outlined above might perhaps be extended to examine the effect of IVRGI on road safety but such considerations, along with the question of modelling the possibly important impacts of IVRGI on trip timing, mode choice or trip frequency, are beyond the scope of the present paper (but see Mahmassani and Jayakrishnan, 1989; Van Berkum and Van der Mede, 1990).

In the context of a research programme to investigate the fundamental aspects of dynamic route guidance, the author, together with colleagues at the Universities of Leeds, Southampton and York, is 
currently involved in the specification of new models with which to investigate route guidance. A structure such as that outlined above is one of those under consideration. The hope is that the new model will not only provide a basis for investigating the impact of IVRGI but will represent a significant advance in route choice modelling per se.

\section{CONCLUSION}

This paper has discussed the possible influence of IVRGI systems on network performance and has concluded that this influence will be very dependent on the way in which IVRGI affects drivers' choice of routes.

Evidence as to the complexity of the route choice process has been presented and some behavioural constructs have been discussed. It has been noted that most network models currently incorporate a highly simplified representation of the route choice process.

Evidence on drivers' reactions to route guidance, based on field studies among users of the LISB route guidance system in Berlin and on the results of the interactive simulation model IGOR, was presented. It was noted that most drivers accept guidance selectively and that their reaction is conditioned by the quality of the advice and the existence of any corroborating or conflicting evidence.

Existing models of IVRGI systems were described prior to the specification of a possible new model which might build on the strengths of previous modding work and make use of the newly available evidence on drivers' response.

Acknowledgements: This paper would not have been possible had I not been involved in studies financed the UK Science and Engineering Research Council and the EC DRIVE initiative. The SERC study, based at the Leeds, Southampton and York Universities is entitled "Fundamental Aspects of Route Guidance". The DRIVE study is entitled "The Integration of Route Guidance and Traffic Control". Some of the data presented in this paper was collected within the DRIVE project and the contributions of INRETS (France) and Mizar (Italy) to that process are gratefully acknowledged. Finally, I should like to thank colleagues Tim Parry and Matthew Joint for their contributions to the work on which I have drawn for parts 3 and 4 of the paper and to Dirck Van Vliet, Tom Van Vuren, David Watling for their contributions to discussions prior to and during my formulation of the model outlined in section 7 of the paper. I must stress, however that the views of the organisations and individuals identified above cannot be assumed to concur with those expressed in the current paper.

\section{REFERENCES}

1) Al-Deek, H., Martello, M. , May, A. D. and Sanders, W. : Potential Benefits of Invehicle Information Systems in a Real Life Freeway Corridor under Recurring and Incident Induced Congestion, Proc. first VNIS conf., Toronto, IEEE, 1989.

2) ASTERIX : Extension of Selected Simulation Packages, Deliverable 2 of the V 1054 project : System and Scenario Simulation for Testing RTI Systems, DRIVE Office, Brussels, 1989.

3) Ayland, N. : Evaluating Real Time Responses to In-Vehicle Driver Information Systems, Proc. DRIVE Conference, DRIVE Office Brussels, February 1991.

4) Ben Akiva, M., Bergman, M. J., Daly, A. J. and Ramaswamy, R. : Modelling Inter Urban Route Choice Behaviour, in Volmuller, J. and Hammerslag, R. (eds.), Proc. ninth Internation Synposium on Transportation and Traffic Theory, pp. 299-330, VNU Science Press Utrecht Netherlands, 1984.

5) Benshoof, V. A. : Characteristics of Drivers' Route Selection Behaviour, Traffic Engineering and Control, II, pp. 604-606, 1970.

6) Bonsall, P.W. nad May, A. D. : Route Choice in Congested Urban Networks, in Research for Tomorrows' Transport Requirements, Proc. WCTR Vancouver, pub UBC Vancourver, BC Canada, pp. 1407-1425, May 1986.

7) Bonsall, P. W. nad Parry, T. : Drivers' Requirements for Route Guidance, Proc. of Third International Conference on Road Traffic Control, May 1990, CP 320, IEE London, 1990 a.

8) Bonsall, P. W. and Parry, T. : A Computer Simulation Game to Determine Driers' Reactions to Route Guidance Advice, Proc. 18th PTRC Summer Annual Meeting, PTRC London, 1990 b. 
9) Boyce, D. E. : Route Guidance Systems for Improving Urban Travel and Location Choices, Transportation Research 22 A (4). pp. 275-282, 1988.

10) Breheret, L., Hounsell, N. B. and McDonald, M. : The Simulation of Route Guidance and Traffic Incidents, paper presented at UTSG Conference, Hatfield Polytechnic UK, Jan 1990

11) Brett, A. C. and Estlea, J. : Electronic Route Guidance to Electronic Road Pricing: the next step ?, Proc. 17th PTRC Summer Annual Conference, PTRC, London, 1989

12) Burrell, J. E. : Multiple Route Assignment and its Application to Capacity Restraint, in Leusbach, W. and Baron, P. (eds.). Proc. Fourth International Symposium on the Theory of Traffic Flows, Karlsruhe, Germany, 1968.

13) CARGOES : Integration of Dynamic Route Guidance and Traffic Control Systems, Specification of DRIVE project V 1011. DRIVE Office, Brussels, 1989

14) CARGOES : Analysis of Stability Properties of Route Guidance Strategies, Deliverable 14 of the V 1011 project : Integration of Dynamic Route Guidance and Traffic Control Systems, DRIVE Office, Brussels, 1990 a.

15) CARGOES : Drivers' Requirements for Route Guidance Advice, Deliverable 18 of the V 1011 Project : Integration of Dynamic Route Guidance and Traffic Control Systems, DRIVE Office, Brussels, $1990 \mathrm{~b}$.

16) CARGOES : Drivers' Reaction to Route Guidance Advice, Deliverable 20 of the V 1011 : Integration of Dynamic Route Guidance and Traffic Control Systems, DRIVE Office, Brussels, $1990 \mathrm{c}$.

17) Chang, G-L, Mahmassani, H. S. and Herman, R. : A Macroparticle Traffic Simulation Model to Investigate Peak-Period Commuter Dicision Dynamics, Transportation Research Record, 1005, pp. 107-120, 1985.

18) Heathington, K. W., Worral, R. D. and Hoff, G. C. : Attitudes and Behaviour of Drivers Regarding Route Diversion, Highway Research Record, 363, pp. 18-26, 1971.

19) Horowitz, J.L. : The Stability of Stochastic Equilibrium in a Two-Link Transportation Network, Transportation Research 18 B, pp. 13-28, 1984.

20) Huchingson, R. D., McNess, R. W. and Dudek, C. L. : Survey of Motorists' Route Selection Criteria, Transportation Research Record, 643, pp. 45-48, 1977.

21) Jeffery, D. J. : The Potential Benefits of Route Guidance, DTp TRRL LR 997, TRRL, Crowthorne, 1981.

22) Jeffery, D. J., Russam, K. and Robertson, D. I. : Electronic Route Guidance by Autoguide--The Research Background, Traffic Engineering and Control, Vol. 28, No. 10, 1987.

23) Jovanis, P. P. and Kitamura, R. : User Perceptions and Safety Implications of In-Vehicle Navigation Systems, Proc. First VNIS Conference Toronto Sept, 1989 IEEE, 1989.

24) King, G. F. : Driver Attitudes Concerning Aspects of Highway Navigation, paper presented at 65 th Annual Meeting of TRB, Washington DC, USA, 1986.

25) Kobayashi, F. : Feasibility Study of Route Guidance System, Transportation Research Record, 737, pp. 107-112, 1979.

26) Koutsopoulos, H. N. and Lotan, T. : Effectiveness of Motorist Information Systems in Reducing Traffic Congestion, Proc. First VNIS conf., Toronto, IEEE, 1989.

27) Mahmassani, H. S. and Jayakrishnan, K. : System Performance and User Response under Real Time Information in a Congested Traffic Corridor, presented at seminar on Urban Traffic Networks Capri Italy June 1989, to be published in Transportation Research, 1989.

28) Mahmassani, H. S. and Stephan, D. G. : Experimental Investigation of Route and Departure Time Dynamics of Urban Commuters, presented at 67th annual meeting of TRB and subsequently published in Transportation Research Record, 1988.

29) OECD : Route Guidance and User Communications Systems, Road Transport Research Paper, Paris, 1988.

30) Outram, V.E. and Thompson, E. : Drivers' Perceived Cost in Route Choice, Proc. of 6th PTRC Summer Annual Meeting, PTRC, London, 1978.

31) Rakha, H., Van Aerde, M., Case, E. R. and Ugge, A. : Evaluating the Benefits and Interactions of Route Guidance and Traffic Control Strategies using Simulation, Proc. First VNIS Conference, Toronto, IEEE, 1989.

32) Shirazi, E., Anderson, S. and Stesney, J. : Commuters Attitudes Towards Traffic Information Systems and Route Diversion, Transportation Research Record 1168, 1988.

33) Smith, M. J. and Ghali, M. : A New Model for Evaluating the Performance of Urban Traffic Control Systems and Route Guidance Strategies, presented at TRB Annual Conference, Washington DC, 1991.

34) Smith, J. C. and Russam, K. : Some Possible Effects of Autoguide on Traffic in London, Proc. First VNIS Conf. Toronto, IEEE, 1989.

35) Stephens, B. W. : Comparison of Alternative Methods for Presenting Trip Navigational Information to Motorists, Proc. 18th PTRC Summer Annual Conference, PTRC London, 1990.

36) Stephenson, B. : Travel Behaviour and Equilibrium in a Network of Signalised Intersections, MSc Thesis, University of Alberta, Canada, 1981.

37) Tsuji, H., Takahashi, R., Kawashima, H. and Yamamoto, Y. : A Stochastic Approach for Estimating the Effectiveness of a 
Route Guidance System and its Related Parameters, Transportation Science 19.4, 1985.

38) Ueberschaer, M. H. : Choice of Routes on Urban Networks for the Journey to Work, Highway Research Record, 369. pp. 228-238, 1971.

39) Van Aerde, M., Voss, J. and Blum, Y. : Modelling the Burlington Skyway during Recurring and Non Recurring Congestion, Traffic Engineering and Control, Vol.30, No. 5, pp. 228-240, 1989.

40) Van Aerde, M. W. and Yagar, S. : Combining Traffic Management and Driver Information in Integrated Traffic Networks, Proc. of Third International Conference on Road Traffic Control May $1990 \mathrm{cp} 320$ IEE London, 1990.

41) Van Berkum, E. C. and Van Der Mede, P. H. J. : A Dynamic Behavioural Model for Route, Mode and Departure Time Choice, Proc. 18th PTRC Summer Annual Conference, PTRC London, 1990.

42) Van Vuren, T., Van Vliet, D. and Smith, M. J. : Combined Equilibrium in a Network with Partial Route Guidance presented at the Engineering Foundation Conference on Traffic Control Methods, Santa Barbara, 1989.

43) Van Vuren, T., Watling, D. : A Multiple User Class Assignment Model for Route Guidance, paper presented at TRB conference Washington DC, 1991.

44) Wachs, M. : Relationships between Drivers' Attitudes Towards Alternate Routes and Driver and Route Characteristics, Highway Research Record 197, pp. 70-87, 1967.

45) Wardrop, J. : Some Theoretical Aspects of Road Traffic Research, Proc. Inst. Civ. Eng. II-1, pp. 352-378, 1952.

46) Watling, D. : Route Guidance Algorithms Effective for all Levels of Takeup and Congestion, ITS WP 315 University of Leeds, 1990.

47) Wooton, J., Ness, M. and Burton, R. S. : Improved Direction Signs and the Benefits for Road Users, Traffic Engineering and Control, 22, pp. 264-268, 1981.

48) Wright, C. C. : Some Characteristics of Drivers Route Choice in Westminster, Proc. 4th PTRC Summer Annual Meeting, PTRC London, 1976. 